\title{
The Social Impact of Home Rehabilitation in Low-Income Neighborhoods
}
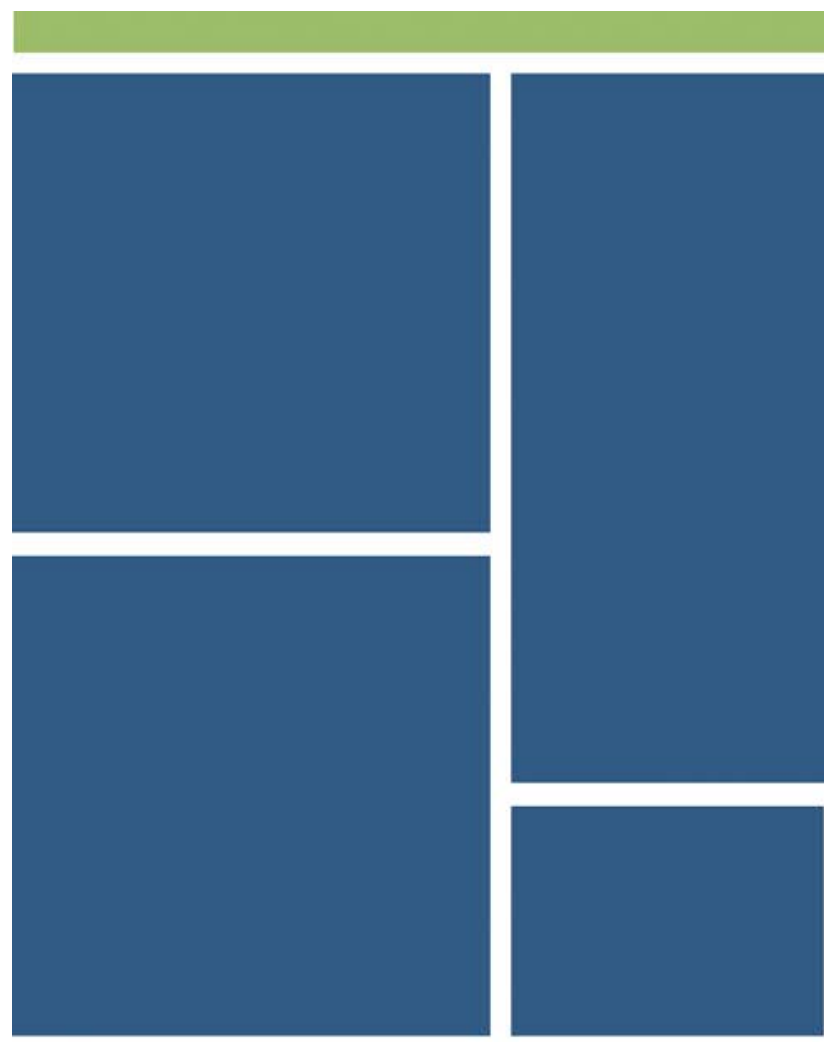

Community

Development

Discussion

Paper
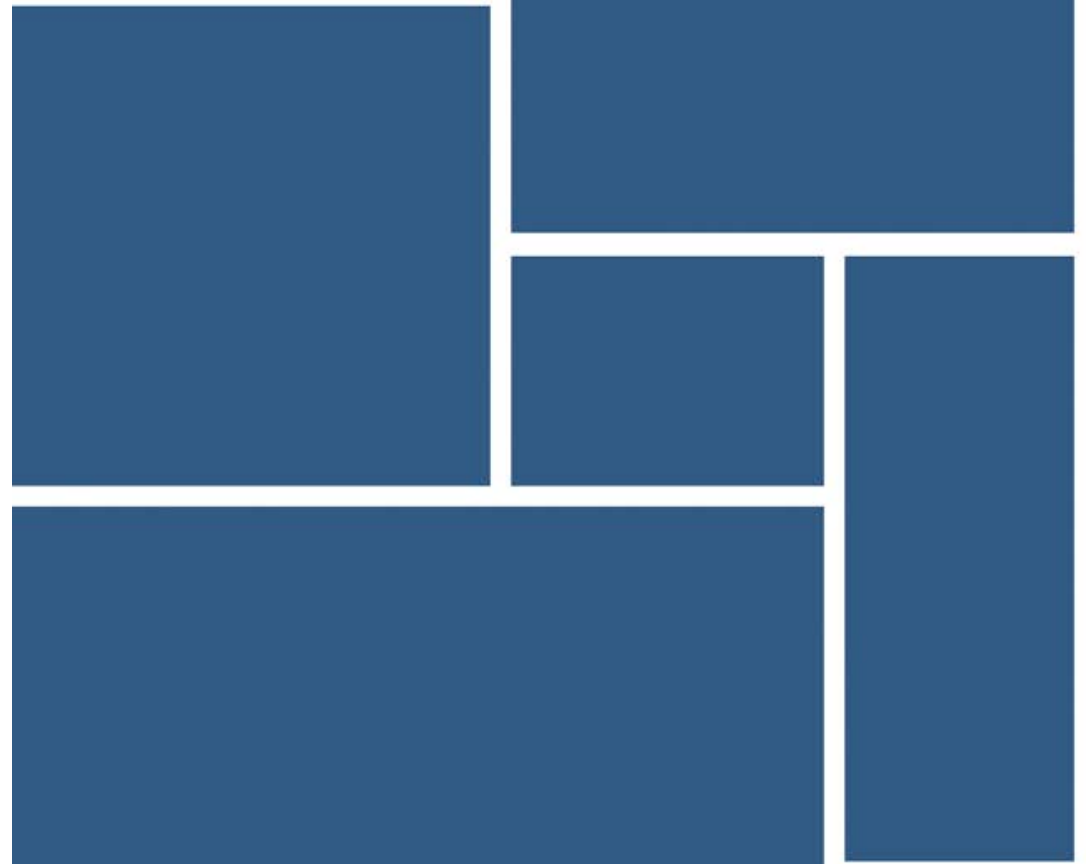


\title{
The Social Impact of Home Rehabilitation in Low-Income Neighborhoods
}

\author{
Erin Graves and Elizabeth Shuey
}

\begin{abstract}
While economists and others have studied the impact of abandoned foreclosed homes on nearby home prices and crime, very few scholars have attempted to understand the impact of abandonment and rehabilitation on neighborhood social conditions. The foreclosure crisis of 2005-2010 led to a concentration of abandoned foreclosed homes in disadvantaged neighborhoods and these neighborhoods became the targets of a policy intervention, the Neighborhood Stabilization Program. This study employs a mixed-method longitudinal approach to investigate the impact of this foreclosed home rehabilitation policy on neighborhood social conditions and physical conditions in a highly disadvantaged neighborhood. We compared this to a quasi-control group of similar abandoned, foreclosed neighborhood homes not selected for the program. Results indicated that the rehabilitation of a foreclosed home had marginally significant negative impact on social conditions and no impact on the physical conditions of nearby homes. There were no differences between the program properties and the control properties, except that the control properties were rehabilitated more quickly. To further explore the quantitative findings, we divide the qualitative results into four major themes emerging from the data: indifference to foreclosures, threats to the neighborhood, call for community cohesion, and the importance of homeownership. These results indicate that the affected residents believe that neighborhood stabilization efforts would have benefitted more from programs that aimed to improve homeownership opportunities and increase neighborhood levels of social cohesion and social capital.
\end{abstract}

Acknowledgments: The authors wish to thank Jeff Fuhrer, Anna Steiger, Ana Patricia Munoz and Kerry Spitzer for their helpful comments. Kerry Spitzer also assisted with the data collection and preliminary analysis.

The views expressed in this paper are solely those of the authors and do not necessarily represent those of the Federal Reserve Bank of Boston or the Federal Reserve System. 
Urban planners, community development professionals and urban policy makers face a perennial neighborhood dilemma that has been exacerbated by the foreclosure crisis: the proliferation of dilapidated and abandoned homes in distressed neighborhoods. Many consider such homes a sign or even a cause of larger intractable neighborhood problems. Abandoned homes in low-income neighborhoods are viewed as "magnets for crime, violence, and other social ills" (Apgar, Duda, Gorey, \& Council, 2005), and they "reduce the value of neighboring homes" (Schwartz, Ellen, Voicu, \& Schill, 2006). One proposed solution has been to rehabilitate these properties, which would presumably reduce the opportunity for crime and its attendant social ills to take hold, while simultaneously raising neighboring housing prices.

Community development corporations focus a substantial portion of their resources on housing, largely through rehabilitation. This focus is partly motivated by an acute need for housing assistance in many low- to moderate-income neighborhoods but also by the perception that housing investment generates positive spillovers to the neighborhood, such as increased home values and improved social conditions (Edmiston, 2012). Limited evidence indicates that rehabilitating abandoned homes elevates neighboring home prices (Gerardi, Rosenblatt, Willen, \& Yao, 2012; Immergluck and Smith, 2006a, 2006b; Schwartz et al., 2006), and a small body of literature attempts to investigate the impact of housing rehabilitation on nearby crime (Cui, 2010; Jones \& Pridemore, 2012; Kirk \& Hyra, 2012; Lacoe \& Ellen, 2012). However, policy makers and researchers have not investigated whether improving the appearance of and finding occupants for abandoned homes leads to more enduring improvements in neighborhood social conditions, beyond home prices and crime, such as those measured by levels of social capital, collective efficacy or sense of community.

In this paper, we address this gap in the literature by examining the impact of abandoned home rehabilitation on neighborhood social relations. We did so by using a quasiexperimental, mixed methods, longitudinal approach: We tracked home conditions and neighbor sentiments before and after neighboring homes had been rehabilitated in both a treatment and control group. Using this method, we attempted to directly assess whether home rehabilitation, an activity common to the diverse pursuits of community development 
corporations, has an impact on social conditions. We used disadvantaged neighborhoods in Boston, Massachusetts, as a test case.

\section{Literature review}

Several bodies of literature attempt to address the neighborhood-level impact of individual home physical distress and home foreclosure. This review separates the literature into three categories: first, literature that examines the price externalities associated with distressed homes; second, studies that look at the relationship between distressed homes and crime; and finally, literature that looks at the relationship between distressed homes and social conditions. The term "neighborhood stability" is an often employed but not uniformly defined term in this literature. For the purposes of this paper, we will use Rohe and Stewart's definition, "improved physical and social conditions and higher property values" (Rohe \& Stewart, 1996), which seems to capture many of the features the research and policy communities associate with higher functioning communities. Throughout this review, we seek to distinguish between research that investigates the potential negative impact of the introduction of abandoned homes and research that seeks to establish the potentially positive impact of rehabilitating abandoned homes, since it seems unlikely that the introduction of a disamenity and its subsequent removal will have equal impacts. We only report on studies that look at the issue of vacant properties, rather than occupied, physically distressed ones. For the most part, these studies use foreclosed properties, rather than properties abandoned due to other forces.

\section{Economic Impact of Distressed Homes}

Economists and others have assessed the economic impact of public investments in housing on the prices of nearby housing. The large scale of the recent foreclosure crisis has allowed researchers to test some of the assumptions about the impact of abandoned homes on nearby home prices. Some studies test for the negative impact of abandoned, often foreclosed, homes on nearby home prices. The types of housing studied vary from single-family homes to multi-family houses to large-scale developments. Several studies have shown that housing divestment negatively impacts nearby home prices. For example, Immergluck and Smith 
(Immergluck \& Smith 2006 b) showed that abandoned homes reduce the price of nearby homes by about $1 \%$. More recently, Gerardi et al. (2012) have shown that a negative effect on prices initiates much earlier in the divestment process - when homeowners become delinquent on their mortgages. Abandoned homes are costly from a municipal perspective as well. Vacant homes often produce no property tax and can be the targets of arson or locations of accidental fires. The decrease in property values also has an impact on public coffers, as tax revenue is reduced.

Other studies investigate the price impact of rehabilitating abandoned homes, specifically in the low-income neighborhood context. Researchers in this arena have produced fairly consistent evidence that rehabilitating abandoned homes increases the prices of nearby homes. Edmiston (2012), using data on homes that sold more than once between 2004 and 2011 in Jackson County, Missouri, reports that housing investments by community development corporations (CDC) "substantially" increased the appreciation of homes nearby. On average, homes within 152 meters (500 feet) of the development projects appreciated, on average $11.8 \%$ more than homes farther away from the housing investment. Researchers were able to limit their analysis to low- and moderate-income neighborhoods in Kansas City, Missouri, which are the typical targets of CDC investments in housing. Schwartz et al. (2006) similarly show that subsidized housing investments in New York City generated significant external benefits in the form of increased property values in the vicinity of the investment. Further, the larger the project, in terms of numbers of housing units generated, the greater the impact (Schwartz et al., 2006). Others suggest that the mechanism for price increases is that the housing investments may increase surrounding property values through a demonstration effect. One study documented that housing investment can lead to additional investment in nearby properties (Goetz et al., 1997), a phenomena sometimes known as "incumbent upgrading" (Clay, 1979).

Who captures the benefits of rising housing prices is less clear. For example, if rising prices are coupled with residential turnover, a new class of higher-rent-paying residents may benefit from the improvement. Long-term renters may be negatively impacted if rents increase to reflect the elevated values of the property. Long-term homeowners, especially those who 
have fixed or low incomes, are negatively impacted by higher property taxes. Additionally, homeownership rates in low-income neighborhoods are usually low. (One neighborhood exhibiting a property value boost due to home renovations had a $20 \%$ homeownership rate). Therefore, the beneficiaries of price increases are often non-resident investors and landlords.

In sum, abandoned, foreclosed homes exert modest negative price externalities on nearby homes, and rehabilitating these homes exerts a modest, positive price externality. However, not all of the above studies were concerned exclusively with low-income neighborhoods, and most authors stress that the economic context of the neighborhood likely moderates the impact on prices. The manner in which the context moderates the price effect is not consistent across studies. Some report that higher income neighborhoods capture more of the benefits, whereas others demonstrate that low-income neighborhoods benefit more greatly from the intervention. Moderation effects are likely more nuanced than simply being a reflection of neighborhood income. In addition, neighborhood crime and the social dynamics within and surrounding a neighborhood may be pertinent to understanding any association between abandoned, foreclosed homes and housing prices.

\section{Relationship between distressed homes and crime}

Many findings about the impact of home foreclosure on crime are mixed. Studies report different kinds of crime, the two most common distinctions being property crime and violent crime. For example, Ihlanfeld \& Mayock (2012) report that the proportion of real estate-owned properties (REOs) at the neighborhood level has a significant impact on crime in the immediate area of a property. However, this effect is only seen for property crime. Using Chicago area foreclosure and crime data for the year 2001, Immergluck and Smith (2006b) find that a 1 SD increase in the foreclosure rate is associated with an increase in neighborhood violent crime of approximately $6.7 \%$. However, in this case, they did not find a statistically significant effect for property crime. Immergluck and Smith relied on cross-sectional data, leaving open the possibility that their results are biased by omitted variables. Of this method, Cui (2010) notes that "higher neighborhood foreclosures are likely to be correlated with unobserved neighborhood factors that determine crime rates." Two studies employ difference-in- 
differences models to relate foreclosures to nearby crime. Cui (2010) compares violent crimes and property crimes within 76 meters ( 250 feet) of a foreclosure filing to those that occur within a range of 76 to 108 meters (250 to 353 feet) in Pittsburgh, Pennsylvania. The results show that violent crimes within 76 meters ( $250 \mathrm{feet}$ ) of the foreclosed home increased by more than $15 \%$ after the foreclosed home became vacant compared with crimes that occurred within a range of 76 to 108 meters (250 and 353 feet) from the foreclosed property. However, Jones and Pridemore (2012) found no evidence that housing mortgage distress and either crime rate or property crime were correlated. Using a random effects model, Kirk and Hyra (2012) also failed to find that foreclosure and crime exhibited a significant association.

Most recently, New York University's Furman Center for Real Estate and Urban Policy reported a significant increase in crime near foreclosed homes but only in areas that had three or more foreclosures clustered together. However, some scholars strongly dissent, arguing that foreclosure and crime are not causally associated, instead attributing the apparent association to confounding variables (Kirk \& Hyra, 2012).

Lack of consensus regarding the impact of foreclosed homes on the incidence of crime is paired with theoretical disagreement about how home distress might lead to crime. $\mathrm{A}$ sociological axiom linking housing blight to crime is the "broken-windows theory," which holds that minor problems in a neighborhood, such as property distress (or its symptoms, such as broken windows) may lead to increased levels of more serious crime (Wilson \& Kelling, 1982). Spelman (1993) argues further that, in the case of abandoned homes, vacant properties and crime are more strongly associated than suggested by the broken-windows phenomenon. Vacant properties often become inhabited by squatters and develop into breeding grounds for crime, particularly drug dealing and prostitution. More serious violent crimes often follow the lesser crimes. Some studies have offered evidence in support of this phenomenon in cities such as Baltimore (Taylor, Shumaker \& Gottfredson, 1985), Chicago (Sampson \& Raudenbush, 1999), and Philadelphia (Brown, Perkins \& Brown, 2004). 


\section{Impact of housing distress on social conditions}

Beyond crime rates, very few studies attempt to measure the impact of neighborhood divestment or reinvestment on neighborhood-level social relations. There has been scant empirical research on the social impact of home abandonment, despite strong theoretical support regarding the negative impact of population loss on social relations. For example, proponents of social capital theories suggest that it is less the physical distress of a home than the loss of its occupants that places negative pressure on social conditions. The neighborhood loses members of its social group when the household exits, thus reducing social cohesion at the neighborhood level. Sampson outlines "the destabilizing potential of rapid population change on neighborhood social organization. A high rate of residential mobility, especially in areas of decreasing population, fosters institutional disruption and weakened social controls over collective life." This is because it takes time to form meaningful social relationships, or even to develop enough community trust to enforce social norms. Some argue that blighted properties themselves not only reduce the physical attractiveness of the neighborhood but also are thought to cause a variety of social problems (Edmiston, 2012). Other surveys have shown the physical appearance of the neighborhood to be a critical component of neighborhood satisfaction (Hur and Morrow-Jones, 2008).

However, very few studies have attempted to measure the social impact of home rehabilitation. We found no tests attempting to assess the impact of improving the appearance of blighted neighborhoods. The thin literature on the impact of housing revitalization on neighborhood social conditions may result in part because scholars and practitioners disagree about the likelihood that physical revitalization will improve neighborhood social relations. On the one hand, the broken-windows theory explains why abandoned homes are associated with crime, divestment and social disorder. Consequently, proponents maintain that the physical rehabilitation of abandoned buildings will improve the quality of life for neighborhood residents by increasing the projected sense of community efficacy and therefore discouraging crime. But again, the introduction of a disamenity (broken windows) and its removal may not have equal and opposite impacts. The broken-windows theory has been adopted into community revitalization efforts that aim to create the visual sense of a neighborhood among residents 
who maintain their homes to increase the sense of community efficacy. For example, the International City/County Management Association advises local governments on how to encourage the revitalization of vacant properties directly, citing the broken-windows theory (Schilling, 2002).

The practical literature often cites the social impact of home distress and revitalization. For example, some maintain, "When foreclosures are filed and homeowners leave, the social fabric of communities is frayed" (Nelson, Petrus and Richter, 2011). The National Vacant Properties Campaign notes that "a large number of vacant buildings in the neighborhood symbolizes that no one cares" (National Vacant Properties Campaign, 2005). The president of the Federal Reserve Bank of Boston, Eric S. Rosengren, argues that foreclosed homes are associated with "depressed home prices, but also a host of other community problems (Rosangren's emphasis)." A spokesman for the former Chicago community development organization Shore Bank noted, "A house owned by a bank is boarded up, so it's all very counterintuitive to a sense of community" (Umberger, Yerak and Malone, 2008).The Local Initiatives Support Coalition in an annual report stated, "Building and preserving affordable homes and other real estate is a cornerstone of community development... . It is, in short, crucial to the strength of neighborhoods" (Local Initiatives Support Coalition, 2009). However, the broken-windows theory's skeptics include its own originator: Its author, James Q. Wilson has noted that the theory lacks substantive scientific evidence that it works. "I still to this day do not know if improving order will or will not reduce crime... . People have not understood that this was a speculation" (Hurley, 2004). As noted above, some assert simply that the theory conflates causation and correlation (Kirk \& Hyra, 2012). Sampson et al. (1997) reject the notion that the bricks and mortar of physical renovation will create the needed social change to prevent crime and disorder that is central to the broken-windows theory. They argue that the most important influence on neighborhood crime is neighbors' collective efficacy or willingness to act, when needed, for one another's benefit. Research shows that collective efficacy exerts an influence over a neighborhood's crime rate strong enough to overcome the far better known impacts of race, income, family and individual temperament. Contrary to the broken -windows 
theory, Sampson et al. found that most major crimes were linked not to "broken windows" but to two other social neighborhood variables: concentrated poverty and collective efficacy. Moreover, many reference the macro-level negative social and economic forces such as deindustrialization, suburbanization and, most recently, the global housing crisis that contribute to home foreclosure and abandonment in disadvantaged neighborhoods. As the National Vacant Properties Campaign (2005) notes, "The root of the problem may seem far beyond the control of local governments. The vacancies are often the result of larger forces, such as corporate decisions to transfer jobs overseas, or developers' decisions to invest in sprawling new homes far on the urban fringe." It is not clear how home rehabilitation can countervail these forces.

However, while disagreement exists about how the rehabilitation of abandoned homes exerts influence on social conditions, there is much greater consensus about the importance of positive social conditions in disadvantaged neighborhoods - regardless how they are produced. At a basic level, when neighborhoods have weakened or community systems are nonexistent, they cannot serve as a resource for its residents (Brodsky, O'Campo and Aronson, 1999). Social scientists measure the strength of a community system in various ways. The wellknown concept of social capital originated in the fields of sociology and political science to explain how residents within certain communities cooperate with each other to overcome social problems. Social capital, as defined by its main theorists (Coleman, 1988; Putnam 1993), consists of those features of social organization - such as networks of secondary associations, high levels of interpersonal trust and norms of mutual aid and reciprocity. These features can act as resources for individuals and facilitate collective action (Lochner, Kawachi, and Kennedy, 1999).

Although several other definitions and measures of social capital have been proposed, there is enough agreement to make some generalizations about the nature of social capital. Most importantly, social capital is a collective dimension of society external to the individual. Sampson et al. (1997) expanded upon the concept of social capital and proposed a form of social capital labeled "collective efficacy." Collective efficacy is neighborhood-level social cohesion combined with a willingness to act on behalf of the common good; it is a determinant 
of neighborhood violence. Collective efficacy definitions share the "notion that group members believe in the overall ability of the collective to act effectively" (Lochner, Kawachi, and Kennedy, 1999). As Sampson, Morenoff, and Gannon-Rowley note, many indicators of neighborhood mechanisms are inter-correlated (Sampson et al. 2002). The discipline of psychology developed the concept of a psychological sense of community. Sense of community is a related concept to collective efficacy. It includes several individual items that tap into the same indicators of a community's stock of social capital as defined by Putnam (1993). Additionally, sense of community refers to a collective characteristic, not to individual relationships and behaviors (Lochner, Kawachi, and Kennedy, 1999).

Across bodies of literature and various disciplines, studies have shown that locales where neighbors share a perceived sense of similarity and feelings of interdependence experience both lower levels of crime and other positive outcomes, even when controlling for other socio-demographic characteristics. Some studies have demonstrated that weaker social ties directly increase the likelihood of crime (Sampson \& Groves, 1989; Bellair, 1997). Sampson et al. (1997) showed that after controlling for individual-level socio-demographic characteristics, neighborhood collective efficacy shows a strong inverse association with measure of perceived neighborhood violence, violent victimization and homicide events. Higher levels of social capital, collective efficacy and sense of community can mediate some of the negative processes associated with disadvantaged neighborhoods beyond direct measures of crime. For example, several studies have shown that higher informal social control is negatively associated with adolescent problem behavior (Elliott et al., 1996; Sampson et al., 1997), after controlling for structural levels of disadvantage and individual characteristics. Davidson and Cotter (1991) found that a positive sense of community is associated with increased political activity and voting behavior. Others found that sense of community mediated the impact of neighborhood disadvantage on juvenile delinquency (Cantillon, 2006). Thus, across various measures of neighborhood social conditions, research shows that enhanced social conditions of disadvantaged neighborhoods can have a powerful mediating effect on various negative impacts of disadvantage. 
Some do disagree with community development's focus on improvement to neighborhood-level social relations because such a focus places the importance of intraneighborhood relationships above inter-neighborhood relations. Empirically, for example, some show that after controlling for neighborhood structural characteristics such as homeownership, social cohesion is not related to crime (Greenberg, Rohe \& Williams, 1982; Perkins et al., 1993) and that crime is most influenced by structural variables (Sampson \&Wilson, 1995). That is, improving how neighbors interact with one another likely does little to help structural disadvantage. In the case of sense of community, while the beneficial effects of a psychological sense of community are less controversial, some object to the emphasis on local community. The concern is that a focus on community development in neighborhoods may distract attention from the broader political economy (Nassar \& Julian, 1995). Similarly, Sampson notes that collective efficacy is embedded in structural contexts and a general political economy that stratifies neighborhoods by key social characteristics. Thus, neighborhood social and economic processes, such as low housing values and high crime, are primarily a result of dynamics that sort residents in the metropolitan area and, secondarily, dynamics within a neighborhood.

Others note, however, that social capital can take several forms, some of which are more likely to help individuals and groups advance socially and economically. Later social capital theory distinguishes between "bonding," "bridging," and "linking" forms of social capital (Narayan 1999; Woolcock 1998). Bonding social capital involves trust and reciprocity in networks where members know one another and concerns the process of "getting by" in life on a daily basis. However, "getting ahead" occurs through bridging and linking capital. Bridging social capital occurs when members of one group connect with members of other groups and access support or gain information. Linking social capital involves social relations with those in authority, which might be used to garner resources or power (Stone and Hughes, 2002). Thus, in disadvantaged neighborhoods residents who can enhance their bridging and linking social capital increase their chances of getting ahead.

Possibly because there is such a loose relationship between social theory, which precisely identifies the mechanisms linking home rehabilitation to social conditions, and the practical act of home rehabilitation, rigorous tests of the thesis that rehabilitating abandoned 
homes improves an area's social conditions, such as levels of social capital or sense of community, have not been established. Given the literature, there are several reasons to believe that rehabilitating abandoned homes will have little impact on social conditions. First, one of the strongest correlates of positive social conditions is tenure: Rehabilitation, at least in the short term involves bringing new households into the neighborhood. The second correlate of positive social conditions is high socio-economic status. Rehabilitation can increase nearby home prices modestly and therefore compensate nearby property owners for the losses sustained due to the externally caused abandonment. However, rehabilitation likely cannot serve as a catalyst for improvements in the neighborhood housing market. There are no established links between the kinds of price increases associated with rehabilitation and a general improvement in the types of neighborhood social and economic conditions that encourage current residents to stay or new residents to invest. Without an accompanying improvement in neighborhood social conditions, such as lower levels of crime or improvements in school quality, it is hard to imagine how these price increases can be suggestive of economic development. On the other hand, there is some reason to believe that rehabilitating homes will have a positive impact on social relations. Home abandonment appears to have a negative impact on neighborhoods and there may be an inverse, if not proportional, impact of rehabilitation and the accompanying repopulation. Moreover, many practitioners, after engaging in the work of home rehabilitation and revitalization have observed the positive impact of these efforts, and there is a significant body of anecdotal evidence substantiating this view.

Of course, most community development organizations do not only renovate homes. Some also seek to re-occupy those homes with homeowners. However, other organizations target rehabilitated homes for other kinds of tenure, such as affordable rental or transitional housing. Almost all organizations complement their rehabilitation efforts with other community building efforts, such as youth programs or job training assistance. Most recently, organizations have aimed to address simultaneously the neighborhood-level variables that are thought to influence individual outcomes, such as housing, education, employment and health. Yet with so much time, money and confidence invested in the thesis that home rehabilitation leads to 
improved social conditions, it seems appropriate to put this idea - in isolation - to the test. In this study, we directly tested the thesis that rehabilitating abandoned homes improves neighborhood-level social conditions.

\section{Methods}

The scale of the current housing crisis allowed for a test of the social impact of home rehabilitation on neighborhood social conditions via a quasi-experiment that compares homes slated for rehabilitation through a federal foreclosure intervention program with similar homes not included in the program. The foreclosure intervention policy of interest, the federally funded Neighborhood Stabilization Program (NSP), awarded the City of Boston several million dollars to acquire, rehabilitate and resell abandoned, foreclosed homes in Boston's highforeclosure neighborhoods. The goal of this study was to assess whether the NSP would have an impact on neighborhood social conditions during its first year of implementation. To answer this question, we employed a longitudinal, mixed-method, quasi-experimental design.

\section{Quasi-experimental design}

Neighborhoods targeted by the NSP are those with high rates of foreclosures; thus numerous eligible properties in Boston's NSP target neighborhoods were not acquired by the city for rehabilitation. The limited nature of the NSP funds and the neighborhood selection criteria for NSP properties therefore created a unique opportunity to compare program impacts for properties purchased by the City of Boston with NSP funds with comparable properties in the same neighborhoods that did not receive municipal intervention but rather became real estate-owned (REO) through the foreclosure process. The fact that NSP intervention properties and REO foreclosures were present in the same neighborhoods is key to addressing issues of neighborhood context in the assessment of NSP impact. Boston's high-foreclosure neighborhoods are also among Boston's highest crime, lowest-income and most racially segregated neighborhoods (Boston Police Department, 2009; Boston Redevelopment Authority, 2010), meaning that the NSP was launched in neighborhoods facing multiple types of disadvantage aside from foreclosures. 
To take advantage of the varying circumstances of foreclosed properties within neighborhoods created by the NSP intervention, we selected eight pairs of properties. Each pair consisted of similar abandoned, foreclosed properties in the same neighborhood - all were two- or three-family homes in the areas of Dorchester and Roxbury. However, one property in each pair was from the list of properties acquired by the City of Boston using NSP funds over the six-month period preceding the Year 1 data collection and comprised our treatment group. The other property in each pair was not acquired with NSP funds and was REO at Year 1; this group of properties formed our control group, allowing us to track what might happen to abandoned foreclosed homes absent the NSP.

In order to assess the impact of the NSP on neighborhood social conditions, our respondent sample included all residents of buildings that directly abutted the treatment and control properties. That is, all buildings that were one house away from the abandoned house and all buildings directly across the street from these houses. Figure 1 illustrates a typical block and the dwellings considered in our sample. In certain instances, we expanded these criteria for inclusion of a property when, upon visiting the block, we noted that a building outside of this immediate area had a clear view of the house, and thus residents of the building would be aware of and potentially affected by the abandoned building. We focused on this limited set of respondents, as we expected the NSP to have the greatest impact on residents living closest to the abandoned buildings (Cui, 2010; Edmiston, 2012). Throughout the rest of this paper, we use the phrase "NSP properties" when referring to the treatment properties acquired with NSP funds; "control properties" when referring to the abandoned, foreclosed homes that remained in the private market; and "target properties" when referring to both the treatment and control properties versus "abutting properties," which are the properties surrounding the target properties. The term "parcel" refers to the physical properties, regardless of occupancy or treatment status. 


\section{Figure 1: Typical Study Neighborhood}

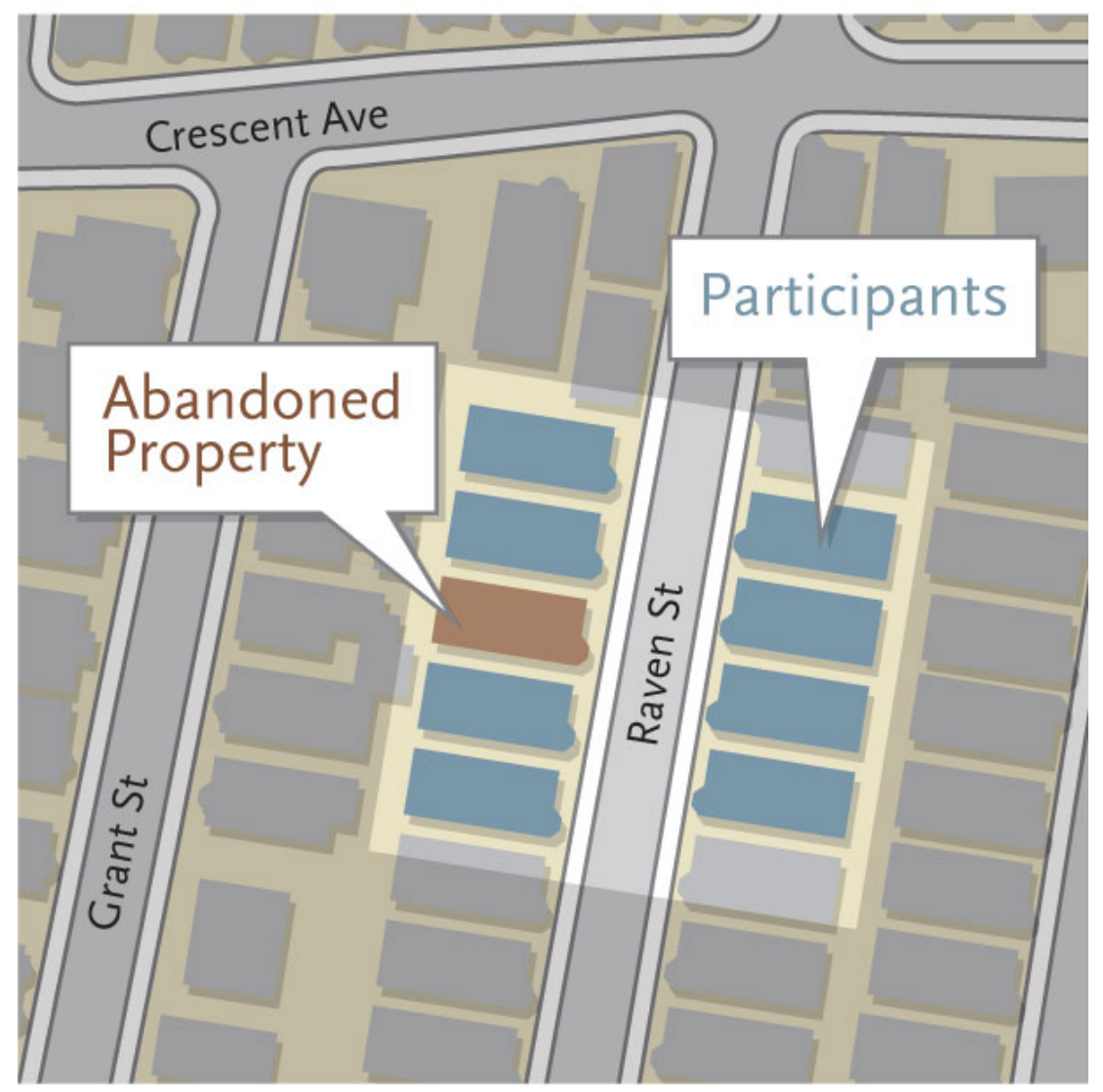

Source: Federal Reserve Bank of Boston

\section{Mixed methods procedures}

The research team visited every street, assessed the condition of every parcel, and attempted to conduct at least one in-person interview at every unit.

Parcel Condition. Across the 16 blocks, a total of 138 parcels were included in the sample. Parcel condition was assessed using 12 items (see the Appendix) rated by observers and drawn from standard forms in the urban planning field. The reliability of this scale was good ( $\alpha=0.81$ and $\alpha=0.72$ for Year 1 and Year 2, respectively), and descriptive statistics are presented in Table 1. 
Table 1: Parcel data for 2011 and 2012

\begin{tabular}{lll}
\hline & 2011 & 2012 \\
\hline Mean & 32.99 & 27.01 \\
SD & 23.92 & 17.31 \\
Min. & 0 & -5 \\
Max. & 110 & 75 \\
\hline
\end{tabular}

Source: Authors' calculations

In-person survey

Based on a resident list maintained by the City of Boston, 547 adults resided in the 138 parcels included in our sample in 2011 and 564 adults resided in the units in 2012. In both years, two-person research teams rang the doorbell or knocked on the door at each of these units between the hours of 2 p.m. and 8 p.m. on weekdays and Sundays in the months of June and July. If someone answered the door, we introduced ourselves and explained the survey. If a resident was willing to participate, we administered the survey in the entryway or, in some instances, inside the respondent's home. All residents present and over age 18 were given the opportunity to participate in the survey, and all participants were compensated with a money order for US\$20. In a few instances, residents indicated that they were not interested in participating, in which case we removed the unit from our list. If no one answered the door, we left a flyer that included our phone number and brief information about the survey.

Respondents were first asked general questions about the amount of time they had resided at their current address, as well as about their status as homeowners or renters. Next, respondents answered eight questions on a Likert scale (see the Appendix) about their sense of community in their neighborhood, defined as the area they could see from their front doors. The sense of community questions were drawn from a validated survey (Peterson, Speer \& McMillan, 2008) used in the community development field, and reliability was good ( $\alpha=0.70$ and $\alpha=0.72$ for Year 1 and Year 2, respectively). Respondents were also asked about their participation in different types of neighborhood organizations. In addition, respondents answered questions about the target property on their block, including questions about the 
renovation process at Year 2. At Year 1, respondents also were given the opportunity to talk in an open-ended fashion about their neighborhoods and were asked: "What do you think influences home prices on your block?" At Year 2, they were asked: "What would make your block a more desirable place to live?" Finally, demographic data were collected from respondents, including gender, age, race/ethnicity, marital and employment status. We also included a standard measure of resident perceptions of neighborhood environmental factors (e.g., walkability and safety), which previous research has associated with social variables (Wood et al., 2008). We administered 58 and 65 surveys using this outreach method in Year 1 and Year 2, respectively. This represents roughly $10 \%$ and $11 \%$ of our anticipated sample of adults for Year 1 and Year 2, respectively.

\section{Mail survey}

Given the fact that many residents either did not answer their doors or were not home when we visited, we also mailed surveys to units where we had not been able to make inperson contact, using the Dillman Tailored Design Method (2000). The mailed surveys included the same questions as the in-person interviews, but respondents were given space to write in responses to the open-ended questions. To the Year 2 mail survey, we also added a question asking respondents to indicate which neighborhood problem was of most concern to them from a list of four items: safety at night, traffic/parking, abandoned houses, or vacant lots. We based our selection of these items on our experience with the in-person survey during Year 2, as well as themes from the Year 1 qualitative data.

After our initial survey mailing, we sent a reminder postcard to all households that had not responded. Finally, we mailed a reminder letter with a replacement survey to all nonresponding residents in our sample. We personalized all mailings using the Boston Resident List, obtained from the Boston Elections Department. Although this list is updated annually, it is not comprehensive. Nevertheless, it aided in our efforts to use personalized mailings, which are more likely to produce responses than anonymous mailings (Dillman, 2000). If any of the mailings were returned with a "vacant" notation from the postal service, we removed the unit from our mailing list. In Year 1, this mailing method resulted in an estimated total sample of 
410 people, 98 of whom responded to our survey (a response rate of 24\%). In Year 2, 99 responded from a total of 404 (a response rate of $25 \%$ ). The response rates from in-person and mail surveys combined were $27 \%$ in 2011 (146 survey respondents) and 29\% (164 total respondents) in 2012.

For both years, a total of 310 respondents participated in the survey. Sample demographics did not differ significantly from year to year, and we report both years combined in Table 2. Sample demographics also did not differ on the basis of NSP status; however more residents on blocks with an NSP property reported involvement in a neighborhood organization than their counterparts on blocks with a control property $\left(53 \%\right.$ vs. $39 \% ; \chi^{2}[1, N=306]=6.3, p<$ .05), and this difference held for data from both 2011 and 2012.

Table 2: Sample demographics for Year 1 and Year 2, combined $(N=310)$

\begin{tabular}{lll}
\hline & Mean (SD) & $\%$ \\
\hline Years at residence & $11.75(13.16)$ & \\
Age & $46.04(17.04)$ & \\
Homeowner & 26.5 \\
Male & 38.1 \\
Black & 80.6 \\
Hispanic & 12.3 \\
Married & 23.6 \\
Employed & 52.6 \\
Children in home & 40.0 \\
Participation in neighborhood organization & 45.8 \\
Sense of community & $3.28(0.70)$ & \\
\hline
\end{tabular}

Source: Authors' calculations

We collected qualitative data from all of the in-person participants $(N=58)$. In 2011,24 of the mail surveys contained write-in responses. Therefore, in 2011, 92 contained qualitative responses. In 2012, in addition to the 65 in-person surveys that contained qualitative data, 56 mail surveys contained write-in responses. It is unclear why participants more frequently 
generated write-in responses in Year 2 (24 did so in Year 1 and 56 in Year 2). Perhaps it was because in Year 2, we asked two open-ended questions rather than one, and participants could respond to one or both questions.

\section{Longitudinal design}

This study was conducted longitudinally: the first round of data collection occurred prior to the planned intervention (i.e., rehabilitating and reoccupying the foreclosed homes), and the second round of collection took place one year later, at which point all NSP properties were scheduled to have been fully renovated. The same rating scales were used to collect information on parcel condition and sense of community in both years, but the open-ended questions were revised as described earlier on the basis of the initial analysis of Year 1 qualitative data.

In Year 2, we maintained a separate list of residents who had responded in 2011, as these respondents represented a potential participant panel. Of the 144 residents who responded in 2011, 62 responded again in 2012. Panelists were more likely to live on blocks with a higher percentage of owner-occupied parcels $(t[143]=-2.30, p<.05)$, were more likely to be female $(t[138]=2.56, p<.05)$, were Black $(t[141]=-2.36, p<.05)$, were employed $(t[142]$ $=-2.03, p<.05)$, and were less likely to be Hispanic $(t[140]=2.00, p<.05)$, compared with 2011 respondents who did not participate in the 2012 survey. There were roughly equal numbers of panelists from blocks with NSP and control target properties ( $N=32$ and $N=30$, respectively).

\section{Renovation status}

True to the quasi-experimental nature of the study, the trajectory of the NSP and control properties did not proceed as anticipated. First, despite published projections, only half (four of the eight) of the NSP properties were renovated or undergoing renovation in Year 2. Secondly, nearly all (seven of the eight) control group properties had been purchased and were undergoing rehabilitation by Year 2. Target parcels for which the planned renovations had been completed, or for which renovation work had clearly begun (thereby signaling to other 
residents an improvement in the condition of the target parcel), were considered renovated in our analyses.

\section{Analytic approach}

To address the primary question of the study, difference-in-differences regression analysis was used to examine the impact of the NSP on sense of community from 2011 to 2012; however, given that implementation of the NSP was incomplete at Year 2, a more descriptive approach to understanding respondents' experience of foreclosures and property rehabilitation in relation to sense of community was also employed. The quantitative and qualitative analyses were conducted in tandem, with each informing the other in an iterative fashion to make the most of the mixed methods design. A professional transcriber fully transcribed the recorded interviews, and our research team fully transcribed the write-in responses. We then analyzed these transcripts using qualitative data analysis software, which allows users to code the qualitative data by themes.

\section{Results}

NSP impact

Difference-in-differences regressions (Table 3) revealed that a block's NSP status and the residents' associated sense of community did not differ by year. Given that half of the NSP properties remained unrenovated at Year 2, we ran a similar regression focusing on whether renovation had taken place or was underway at Year 2, regardless of NSP status. In this regression, the interaction of a target parcel's renovation status and the survey year was marginally significantly $(p=.08)$ associated with residents' sense of community, such that sense of community declined on blocks where renovations had occurred. Although contrary to expectations that property rehabilitation would be associated with improved neighborhood social conditions, explanations for these findings emerged in subsequent analyses. Thus, these findings are explored in greater detail in subsequent sections that focus on four major themes emerging from the data: indifference to foreclosures, threats to the neighborhood, call for 
community cohesion, and the importance of homeownership. Each of these themes is discussed in turn.

Table 3: Difference-in-differences regression predicting sense of community

\begin{tabular}{lll}
\hline & $\mathrm{B}$ & Robust SE \\
\hline Intercept & $3.32^{* * *}$ & 0.07 \\
\hline City-owned treatment & 0.00 & 0.11 \\
\hline Year is 2012 & -0.12 & 0.11 \\
\hline Treatment $\times$ year & 0.10 & 0.16 \\
\hline Intercept & $3.23^{* * *}$ & 0.09 \\
\hline Property rehabilitated & 0.13 & 0.12 \\
\hline Year is 2012 & 0.11 & 0.13 \\
\hline Rehabilitated $\times$ Year & $-0.29^{+}$ & 0.16 \\
\hline$+p<10 * * * p<.001$ & &
\end{tabular}

Source: Authors' calculations

Indifference to foreclosures

From the very first days of field work, we quickly learned that most residents did not link home foreclosures in particular with a crisis in their neighborhood. In both years, our qualitative data based on face-to-face interactions with residents demonstrated that negative social forces, such fear of gun violence and child safety, caused residents much more concern than the presence of abandoned homes. Many residents, especially renters and younger people, were not even aware that the target home had been foreclosed on. One young woman responded, "I didn't even know it was closed until you told me." A male renter commented, "Wow, it's a foreclosure. Nobody knows about it."

Additionally, contrary to accounts in the popular press, we rarely heard reports of crime in foreclosed homes. One older female owner attested, "No one goes in there [i.e., into the foreclosed house]. If someone went in there the neighbors would call." Another older female owner responded similarly, "I'm watchful and would report anything." Moreover, she reported that the house didn't concern her very much: "[It] hasn't affected the block ..." because "... it's 
not that run down."

Many residents connected the topic of the nearby abandoned, foreclosed home to that of vacant lots also on the block. Their comments suggest that from the residents' perspective, abandoned lots present an equal, if not greater, threat to the neighborhood. A middle-aged female renter referenced the vacant lot next door to her (the foreclosed home abutted her on the other side). In regard to that lot, she commented, "There goes your sense of community." A female middle-aged renter wrote, "There is an empty lot beside my apartment, which needs to be kept up. There are bushes over there and the neighbors throw trash over there, and I wish the city would do something about it." Another female renter noted, "We have vacant lots. They [the city of Boston] need to put something there instead of just trees and weeds." Similarly, another female renter suggested, "If the city of Boston were to maintain its vacant lots and hold property owners responsible for their abandoned lots and units, our neighborhood would prosper much faster." Another female owner said that she and "a few others ... think [vacant lots] are very distracting. It is going to cause people to hang out there, throw trash." These comments suggest that residents associated empty lots with the loss of sense of community and lack of neighborhood prosperity. Notably, vacant lots were largely seen as a city or community problem, with several people noting that city action should be taken.

With one notable exception discussed below, residents' indifference to the foreclosed properties extended into Year 2 and the renovation process at 11 of the 16 target properties. While many residents had taken note of the renovation and approved of the change, very few elaborated or suggested that the renovation signaled a meaningful change for the neighborhood. Typically, our exchange around residents' interaction with the parties renovating the housing proceeded as follows:

Interviewer: So during that process, has the owner or the manager of the property contacted you regarding the property or its condition?

Participant: No, no, no.

Interviewer: And for any reason did you contact anyone about the property?

Participant: No, no, no. We mind our own business. 
The lack of interest is perhaps not surprising, given the relative stability in neighborhood social dynamics from year to year: the correlation for 2011 and 2012 sense of community among the panelists was $r=0.67(p<.001 ;$ similar to findings from other studies, such as Gonzales, Cauce, Friedman, \& Mason, 1996). Further, there was only a slight difference in parcel conditions observed from Year 1 to Year 2. On average, overall parcel scores were higher in 2012 than in $2011(t[137]=-2.74, p<.01$; see Table 1), and the correlation between 2011 parcel scores and change in parcel scores from 2011 to 2012 indicated that parcels in the worst condition in 2011 had the greatest improvements $(r=.74, p<.001)$. However, when the formerly abandoned target properties were excluded from the sample, the difference between 2011 and 2012 scores became non-significant, suggesting that renovations to the target properties had limited impact for the overall physical condition of the block. Nonetheless, when we examined only low-cost parcel conditions items (e.g., presence of flowers, front porch tidiness), we found that Year 2 parcel scores were significantly better than Year 1 scores (t[121] $=-2.11, p<.05)$ for abutting properties. This change may indicate that although residents did not engage in the renovation process on their blocks, there was some trend towards greater upkeep from 2011 to 2012 happening on these blocks.

Further, residents were in many ways isolated from the renovation process. When asked if they had contacted the owner or manager during the renovation process, residents almost always responded that they had not. Similarly, when asked if the contractor or manager had contacted the residents during the renovation process, only one resident indicated that the contractor had initiated contact. The only occasion for interaction appeared to be when residents approached the contractors and offered their services for employment. This occurred at several skill levels; e.g., a neighbor who was a licensed electrician explained how he had been hired by an investor who had purchased one of the control properties out of foreclosure. "We got into communicating and I told him I was an electrician and they called me for a couple of days' [work]." Another resident, who had skills as a painter, approached one of the NSP contractors and received the contract for painting the home's exterior. As his wife recalled, "[My husband] just talked to the guy, [my husband] was out of work and he's been out of work for a long time and he spoke to the guy and he subcontracted him and he painted. They paid 
him and he painted it." In another case, an enterprising neighbor of one of the NSP properties recalled that she had observed that during the renovation process "they had different companies come with the plumbing and such and such. But I was, you know, I was unemployed... . So I was like, you know, you need any help, so he said in September well, you know, possibly you can sweep out the dust." Unfortunately in this case, the contractor did not contact her again regarding the job.

In sum, residents were not engaged with foreclosure issues on their blocks, nor were they engaged with the renovations, except in instances when they took initiative to find work generated through the renovation process. This pattern is also evident in the parcel condition data, which suggest no major improvements to physical conditions on the blocks aside from the target properties. However, despite the general distance residents' reported having from the rehabilitation of foreclosed homes, some small improvements were noted in the low-cost parcel items between Year 1 to Year 2. It is possible that residents felt more motivated to maintain their homes in small ways, given improvements to the foreclosed properties, although the quantitative data did not indicate that these improvements were isolated to blocks where renovations had occurred. Further, given the large percentage of renters on these blocks (roughly 50\%), major improvements to parcels aside from the target properties may not have been up to community members; this may also contribute to indifference about foreclosure, an issue that is explored further as part of the theme around the importance of homeownership.

\section{Neighborhood concerns}

While foreclosed homes were not a cause of great concern for many residents, other neighborhood problems, especially crime and anti-social activity, concerned residents deeply in both Years 1 and 2. Residents voiced their general concerns over lax social control: "Kids are roaming the streets disrespecting elderly and neighbors. Parents have no control over their children." They also offered more specific examples of antisocial and criminal activity, "... We still deal with a lot of violence, drug addicts, and home or auto theft." A young man reported that he saw "prevalent drug dealing and prostitution that occurs around the corner," and another male renter detailed how he saw, "Drug addicts and deals on steps of homes or 
corners; gangs/robbery/assaults." One respondent's plea was typical: "Keep the drug dealers off the street. They all sit in a group, they are all on the corner. If I can take drugs and guns off the street, it will be better for people, and people will sleep good at night." And another resident explained, "My neighborhood is not safe to sit on the porch because they all stand outside in front of your house. Young men selling drugs and fighting with gang members. I wish for a better neighborhood. But it is hard for me to walk to my door because there are people sitting on my porch." In the seemingly hyperbolic words of one resident, "Unsafe, unclean, unpredictable, no values, no morals, no limits, wild, uncivilized, worse than Third World countries."

While residents made reference to many kinds of criminal and antisocial activity, such as gangs, prostitution and property theft, many of them also recalled in detail specific incidences of gun violence. References to gun violence on and near the street with target properties turned out to be one of the most salient themes, particularly in the Year 1 data. Residents on seven of the 16 blocks we visited in 2011 related some episode of gun violence that had occurred on the block. Many times, multiple residents would recall the same instance of gun violence on or near their block. As one female homeowner recounted, "Believe it or not, I have literally witnessed three people lying in the street after being shot. I don't know if you'll recall in the news, Halloween? They shot someone. Another holiday they shot ... a teenage boy." Desires for safer neighborhoods, echoed by many, were exemplified by this plea from a male renter: "If we got rid of the guns, it would be safe." A female Latino renter on another street detailed a personal experience that also affected her perceptions of the social dynamics on the street: "Like, we had two shootings, actually, like, in my apartment. There were bullets coming straight into my apartment last summer, twice. And it was all due to the people who lived upstairs who eventually got evicted. That created, like, a really sense of insecurity on the street." These comments epitomize the experiences of many of the respondents and show the prevalence of gun violence in these neighborhoods. These comments also help to explain why residents did not deem the presence of foreclosed homes as troubling: Foreclosures do not represent the level of threat to residents and their children that gun violence does in the context of marginalized neighborhoods. 
To more directly assess how foreclosures relate to residents' general neighborhood concerns, the Year 2 mail survey asked residents to rank four neighborhood concerns that were frequently mentioned during the in-person interviews. These data (Figure 2 ) indicate that residents had less concern about foreclosed homes and vacant lots than about safety at night -most frequently ranked as the top concern. Of less concern were traffic and parking. In fact, respondents ranked abandoned houses as their least concern.

Figure 2. Year 2 ranking by residents of neighborhood concerns noted during Year 1 in-person interviews

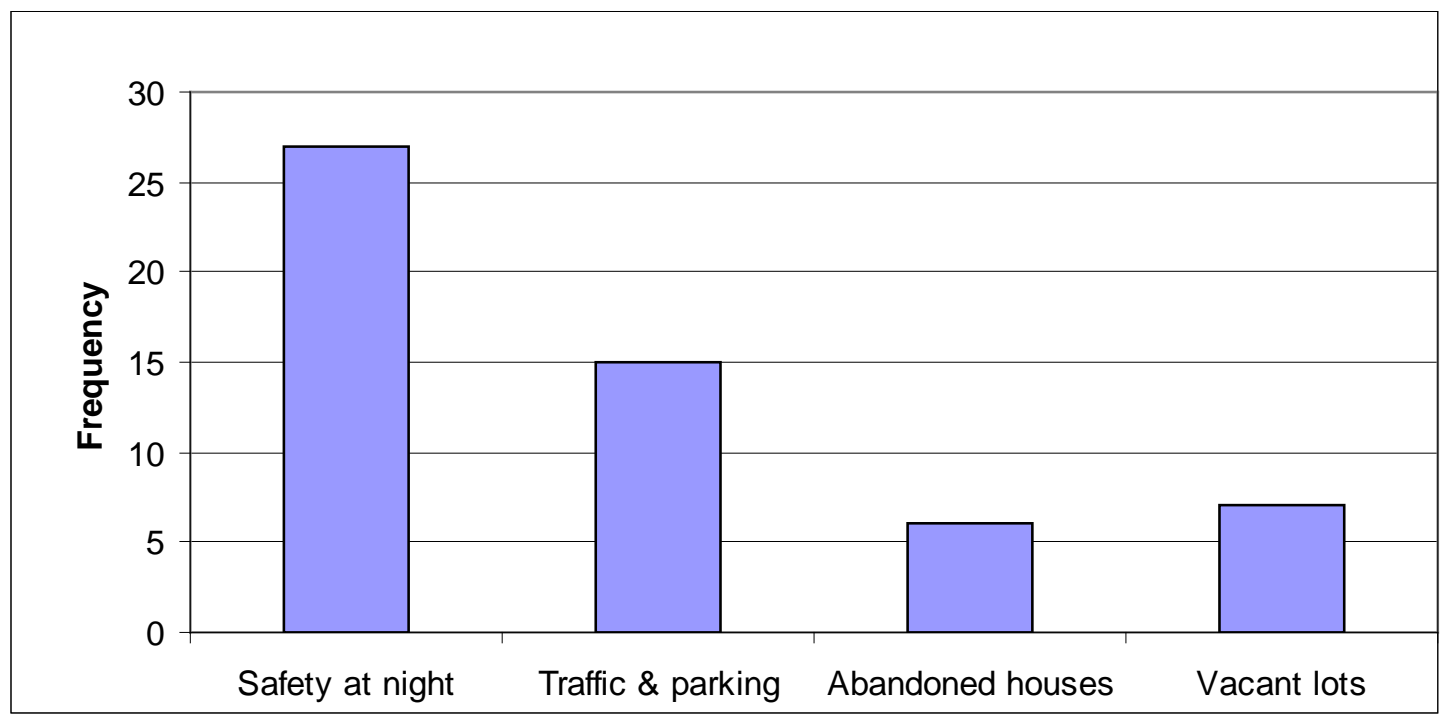


Overall, resident responses indicate a very low sense of social control in the neighborhoods. Issues around social control were among the most frequently coded theme in the qualitative analysis, Residents complained about people engaging openly in anti-social and illegal activity on sidewalks, in vacant lots, and in parks. Since scant formal or informal sanctioning occurs, there may be very little incentive to seek out more covert locations, such as an abandoned home, to pursue these activities. This may be why resident reports of misconduct in abandoned, foreclosed homes are less common than might typically be assumed by outside observers.

\section{Call for cohesion and community engagement}

In both years, many participants identified a need for greater community cohesion to confront their crime and safety concerns they voiced. Often, participants shared their views that stronger local community organizations could be effective in confronting some neighborhood problems and be instrumental in bridging community concerns to city-level actors. As one older female renter recounted, "Over the years, there have been incidences [of crime] but because of the neighborhood association and the community watches [in neighboring developments], it's been controlled." Another elderly female homeowner related that her daughter "... is the Neighborhood Association president. It takes time but can be done." An older male described his neighborhood organization: "So we are very active in the organization, and everybody is quite participating. If anything happens in this community ... there's this issue, we try to solve [it]." Residents recalled participating in a variety of local organizational activities, including meetings, neighborhood watches, marches, vigils, email listservs and neighborhood cleanups, and many engaged with their communities through their places of worship.

Other residents believed that neighborhood participation was necessary to bring about positive change and that residents needed to be more engaged. As one resident noted, people can solve community problems "if they have the right resources." Another resident believed that "my neighborhood should have better organizations, and we all should share our opinions. Also the government should fix things around here." As this comment suggests, many residents 
saw bridging between local and municipal organizations as crucial in promoting neighborhood stability. In fact, many residents recounted collaborations between local neighborhood organizations and extra-local actors, especially the police. One resident "belongs to the neighborhood association which has monthly meetings and gets a lot done, for example, they got stop signs. There is a community officer who reports to the group on the monthly crimes. Encourages everyone to call 911 if they see anything." Another woman recalled working together with neighbors to deal with a group of young men that would hang out at the park, intimidating children. They collaborated with the police and the security company that works at their building and successfully confronted the issue. Similarly, a younger resident noted that "The neighborhood has changed, a lot of the people who have moved in are younger people. So there are a lot of parties [with] noise late at night. But [the neighborhood association] takes care of it. First we talk to them, then if they don't respond we call the police to let them know that we [don't] tolerate this."

While these positive examples of community members coming together illustrate how socially cohesive neighbors can work together to drive resources to their neighborhood, other residents expressed a sense of institutional abandonment and alienation. A few residents communicated their frustration with government services, beyond the city's inability to maintain abandoned lots, as discussed above. One young woman believed that her community's inability to effectively confront problems was "because the state's an ass." Banks were one extra-local institution for which residents expressed an almost uniform lack of confidence and sometimes outright disdain. Often, they connected bank and government behavior. One homeowner expressed frustration with both government and banks and their role in the foreclosure issue. "The city/government is reactive rather than proactive. They wait until they're in foreclosure. Banks are the same. No one is helping people keep their homes." Others place blame squarely on the banks; one person noted, "I wish banks and other lenders could work with owners to avoid these problems," and another neighbor recounted how the owners of a foreclosed property got "swindled" by the banks.

From the participants' comments, the theme of a call for cohesion emerges, revealing that many residents readily identify the role that community groups play in connecting 
neighbors to resources - the concepts of bonding and linking social capital. Residents identified the need for and sometimes the presence of both types of social capital: bonding (i.e., connecting members within the neighborhood network) and linking (i.e., connecting members from within the neighborhood to outsiders with power and influence). Increasing their bonding social capital, participants said, aids in the development of community cohesion and shared norms and interests. Linking social capital helps residents gain better access to municipal resources, like police services.

In Year 2, the call for community cohesion became the most common response (25 out of 107) to the question, "What factors would make your neighborhood a more desirable place to live?" Resident comments varied from an unqualified identification of the need for community groups, such as, "More community activities to know our neighbors." Others tied the need for community groups with help with crime and property protection, "We used to have, way back when, a neighborhood watch and, you know, I don't know what happened to that, but that was something that I remember as being a very good thing when you talk about looking out for each other's homes and stuff like that." In addition to direct calls for community cohesion, residents also made the connection between strong social capital and positive neighborhood conditions, calling for a reduction in social disorder and an increase in policing.

Also new in Year 2, on several target blocks, residents had acted on their concerns about vacant lots and had begun to work together to make significant efforts to remediate the lots. For example, one resident detailed how the local resident group was negotiating with the city to transform a vacant parcel into a community garden. On a separate block, the neighborhood association was working on a master plan to turn a series of vacant parcels into an urban farm. The president of the neighborhood association explained that, "At that time we just said we wanted to look into all the possibilities of what could be on this land besides houses... . So, we used to kind of just get our heads together. Let's do a farm so we can create some jobs for some of these knuckleheads over here. That are sitting around and they're not working and stuff. And having people in the community work on the farms, right? So, that was like the master plan." Other resident groups simply set out to clean up the vacant lots. As one resident recalled, "In between that, it was, like, really bad. So one time ... a group organized a cleanup 
for right here. And ... I prepared food and drinks and they came over, but they were, they gave us garbage bags and plates and things. And we just took up that whole spot over there. Put stuff in the bags and everybody ate chicken and [had] something cold to drink, and it was good." In one case, resident members of a community group sought to transform a troublesome vacant lot into a space they labeled as a sanctuary. "So we want to preserve a little part of it ... just to keep ... some of the natural habitat there, and we want to create something. Sort of like a little memorial for the people that have lost their life to violence. Just to represent, you know, a symbol of peace for the community, but we don't want to distract from what the city wants to do with this, the development that we were fighting badly to bring into the community." Not all residents agreed that the sanctuary would be a success, however, reiterating some of the most salient concerns about crime and antisocial activity: "Who's going to keep the guys out of there from playing cards and drinking beers? Who's going to keep the prostitutes out? ... I'm not saying some day it wouldn't be a great idea. Right now, we have kids in this neighborhood that are dealing drugs and shooting each other."

In Year 2, to some extent, residents answered their own calls for community and worked together to attempt to resolve the abandoned lots issue, which they had identified as a threat to their neighborhood.

\section{Importance of homeownership}

Many residents, both renters and homeowners, viewed homeownership as central to neighborhood well-being, classifying homeowners as actors who maintained stability and renters as forces who threatened it. Residents described homeowners as committed, responsible and admirable community members and contrasted this to the behavior of renters. To some extent, this was born out in the quantitative data, which indicated that in both years owner-occupied parcels were in significantly better condition compared with non-owneroccupied parcels $(t[121]=3.37, p<.01$, and $t[121]=3.88, p<.001$, for 2011 and 2012, respectively).

In the qualitative data, an older male renter maintained a positive view of his block explaining, "There's homeowners and they seem to keep it up." Similarly, a young female 
renter attributed the low level of crime on her street to the presence of homeowners, as well as to older, presumably more-established residents: "I haven't heard any gun shots, which is a plus. [This street has] mainly homeowners and they are older." On the other hand, one middleaged male homeowner attributed instability to renters, arguing, "A lot of people around here now are tenants, not homeowners. ... The tenants are residents, but you know what I mean, they change all the time." Another resident summarized his viewpoint this way: "Because residents have no ownership, they don't care." Other people suggested that homeowners have a particular responsibility to maintain order. As one older female renter stated, "Resident owners should not let groups of people standing in front of their homes smoking, drinking or even being loud with conversation." In response to the question about what could make the neighborhood "more desirable," one respondent wrote, "If the homes were more owneroccupied. Residences/buildings managed by companies have no monitoring and the residents don't care. If people cleaned up in front of their home." A middle-aged male renter explained his feelings of marginalization because of his housing tenure: "It is difficult for renters to feel a sense of ownership and power in a neighborhood like this. Renters are temporary."

Residents often equated long-term residents and homeowners, repeatedly citing longterm residents as a source of stability without direct reference to their homeownership status. Sometimes residents attributed neighborhood stability to their own long-term presence. As one older female homeowner explained, "I've lived in this neighborhood for the past 30-plus years without any major incidents. Neighbors always offered help." Another middle-aged man recounted, "Our family has lived in the house since 1974 and everybody knows me and I know them." A middle-aged female renter linked the high quality of the neighborhood to the presence of long-term residents.

We examined this notion in the quantitative data, regressing home ownership/length of residence on the block on sense of community, while controlling for respondent demographics and block-level homeownership rates and parcel condition (Table 4). The results of this regression indicated that neither individual homeownership nor length of residence on the block were significantly associated with respondents' sense of community but the block-level rate of homeownership was. Thus, individual homeownership may not be central for individual 
sense of community, but the preference for homeowners in the qualitative data is consistent with individuals' feeling a greater sense of community when block-level homeownership rates are higher.

Table 4

Regression Predicting 2012 Sense of Community

\begin{tabular}{lll}
\hline & $\mathrm{B}$ & Robust SE \\
\hline Intercept & $2.71^{* * *}$ & 0.57 \\
\hline Years at residence & 0.01 & 0.01 \\
\hline Age & 0.01 & 0.01 \\
\hline Homeowner & 0.15 & 0.16 \\
\hline Live with family/friends & -0.04 & 0.18 \\
\hline Male & 0.19 & 0.12 \\
\hline Black & -0.08 & 0.17 \\
\hline Hispanic & 0.05 & 0.22 \\
\hline Married & 0.04 & 0.14 \\
\hline Employed & -0.01 & 0.11 \\
\hline Children in home & 0.05 & 0.13 \\
\hline Involved in community groups & 0.14 & 0.11 \\
\hline Rate of homeownership on block & $0.75^{*}$ & 0.32 \\
\hline Average parcel condition on block & -0.02 & 0.01 \\
\hline
\end{tabular}

$* p<.05 ; * * * p<.001$

In addition to a preference for homeowners that emerged in the qualitative data, residents regarded a certain class of residents - those using housing and other social programs - as particular threats to stability. As one older male renter explained, "And I don't like to generalize and category people, but the closer you get to the public housing, and to the, yeah, the closer you get to the end with public housing, it's always a problem at that end. Where the private homes are you never see any police come down here, never any fights, any argument, you know, none of that outlandish language used. Or anything. It's very pleasant on this end." Another older female homeowner expressed a similar view of residents receiving housing 
subsidies, while also implicating the landlords of these properties: "This neighborhood is very noisy all times of the day. Most of this can be attributed to the apartment building on the street and surrounding streets. Most of the tenants are young, on assistance and somewhat transient. I do not believe landlords care." Another older female homeowner attributed the violence occurring on her street to people "running from these [housing] projects over this way." And a third female homeowner detailed how the subsidized housing residents "are not grateful. Government, tax dollars assisting them with the rent. The increase in crime has occurred since they moved in."

Residents also generally opposed the development of supportive housing in the neighborhood. One middle-aged female homeowner complained that "recently a "mental house' was built down the street." Another older female homeowner wrote that she hoped that the abandoned, foreclosed home in question would be rehabilitated and that she "would love to see respectful law-abiding families move in, not rooming house or halfway house." Other residents more explicitly objected to the idea that the new occupants would be on public subsidy: "We don't want any more affordable housing. We, you know - some of the values of our community group. We're - we want to have a community that we're proud of. That we feel that, you know, shows our values, you know? We all have investments in the community. Most of us in this area are homeowners, and so we want to see our property value go up."

Similarly, during the Year 1 interview, one homeowner recounted how she initially objected to the city's plans for the abandoned, foreclosed home to "become a transition home for Little Wanderers [kids aging out of foster care]." However, after the developer had presented the plans before the neighborhood council, she changed her mind and decided, "It will be good if it's done right. New folks, will help them acclimate to life beyond foster care." Indeed, it seems that in this neighborhood the collaboration between the developer and the neighborhood became a success, as the neighbor updated us on the project at Year 2: "For the ages of the children over there, they seem - well, I guess the young adults, I shouldn't call them children, but they seem to be doing pretty well over there. We don't have any trouble. Once in a while, the music may be loud, but that's natural for their age, you know? But I mean, I think it was a good thing what they did ... because they took in people that were homeless ... or 
maybe even in just closet space in someone's house." The neighbor then recalled taking the initiative to host a welcoming party for the new residents. The intent of the party was not simply to introduce the residents to the neighborhood - it was also an opportunity to introduce the new residents to the neighborhood norms: "And then we would just kind of casually say that, you know, we want to work on this thing about parties or whatever."

Residents' unsympathetic view of those receiving public subsidy and assistance shares similarities with the "not in my back yard" phenomenon (NYMBISM) more often associated with higher income and suburban communities. In both cases, residents are likely confounding a host of other socioeconomic characteristics with public subsidy. However, these resident comments also likely reflect the fact that a disproportionate numbers of supportive and subsidized housing units - and their attendant stresses - are located in low-income neighborhoods. Such comments may be not only the outcome of intolerance with the presence of subsidized neighbors but also reflect frustration with the uneven geographic distribution of subsidized and assisted housing.

Moreover, while residents expressed little interest in the renovation process (or as one resident succinctly stated, "Leave well enough alone."), residents showed much more active curiosity about the re-occupation of target properties. For example, when asked, "Do you have any other comments about that renovation process as a neighbor?" the participant responded, "I just hope they put somebody good to live there." Another resident expressed an active curiosity about the identities of the new occupants of a redeveloped NSP property. She described her thought process: "Is it a rooming house or, or he's renting it out to college students, because I see a - or is it some kind of program that the city is covering up, you know what I'm saying ... because of the mixture of the people that are coming and going." Another neighbor explained that when he approached the new owner of a renovated control property he was told:, “He told me it's going to be some - it's going to be Section 8 he's trying to get to."

This mix of interest and concern over newcomers to a recently renovated property may partly explain the quantitative finding that on blocks with renovations, residents reported a somewhat lower sense of community (described earlier and in Table 3). The speculation that 
newly rehabilitated homes are to be occupied by strangers may contribute to this finding. Renovations may signal to residents a disruption in the status quo of a neighborhood block. Lacking knowledge about intentions for the rehabilitated properties likely contributes to residents' worries about who will be moving in next door or down the block.

\section{Interest in ownership}

A subtheme that emerged around homeownership and re-occupancy was an interest among residents in acquiring foreclosed properties. Some residents expressed an interest in taking ownership of the target property, whether it was for themselves, their friends and family or community organizations. For example, one survey respondent wrote, "I feel if my family had a chance to purchase the foreclosed home on our street (our credit is not so good), that would be one less problem." Another neighbor told us how "I have a girlfriend and she was interested in buying it," referring to an NSP target property. However, the participant explained that it was quite difficult to find out any information about the property. Because they couldn't get in touch with anyone from the City of Boston, she explained that they went "out on the deck ... we were looking, she was trying to peek in from my deck to see in that window ... you could see that kitchen from my deck." Another neighbor who lived across from a control property and thought he might purchase it as an investment went into great detail about his repeated and ultimately unsuccessful attempts to learn what institution currently owned the property. After being forwarded to several banks, he eventually gave up. Other residents whom we interviewed indicated that they considered purchasing the property on behalf of their community group. One man explained that his neighborhood organization "even thought about raising the money and buying [the target property] themselves." Numerous residents recounted the difficulties they encountered and the various measures taken to find out whether the property was available for purchase.

Other respondents envisioned explicit policies to enable neighborhood residents to buy properties. "I feel that if programs were available that gave middle- and low-income people a possibility to own their own property it may enhance the community and thereby be kept in better condition." Residents preferred homeowners to renters because homeowners are 
perceived to be invested in the neighborhood. They are viewed as long-term residents and motivated to maintain their properties.

\section{Summary of Themes from Year 1}

Several consistent and sometimes surprising themes arose from our interactions with residents of distressed neighborhoods who participated in our survey:

(1) Residents who could see an abandoned, foreclosed home from their front door did not regard these homes as important threats to neighborhood stability. However, these residents described the threats posed by abandoned neighborhood lots.

(2) Residents described deep concern about other crises affecting residential life, specifically gun violence, child safety, idle youth, and antisocial behavior. These were deemed to contribute more to neighborhood instability than the housing crisis in their neighborhood.

In fact, the qualitative analysis showed that residents spoke about other negative neighborhood forces (108 comments) twice as frequently as foreclosure issues (45 comments). To address these threats, residents called for cohesion. Repeatedly, residents discussed the need for residents to work together toward common goals and to join with institutions within and beyond the neighborhood to achieve stability and thus enhance both their bonding and linking social capital. Similarly, homeownership emerged as a key theme, with residents noting its role in promoting neighborhood safety and stability. Regardless of their own ownership status, residents identified homeowners as the key sources of stability in the neighborhood.

\section{Summary of year 2}

While in Year 1 residents on all blocks lived near an abandoned foreclosed home, in Year 2 , the state of the target homes varied. (Implementation of the NSP program is the subject of a separate analysis; Graves, 2013.) The state of the homes in Year 2 included abandoned, undergoing renovation, renovated but unoccupied, and renovated and occupied. 
In Year 2, despite the fact that not all target properties had undergone renovation, several themes persisted.

(1) Residents' relative lack of concern about the impact of foreclosed homes in their highforeclosure neighborhood as compared with their level of concern about other de-stabilizing forces within the neighborhood. Again, despite the fact that out interviews and survey were explicitly about foreclosure, residents made fewer comments regarding the foreclosed home or foreclosure issues (34 comments) than other neighborhood issues and stressors (122 comments). In cases where the home had undergone a renovation in the previous year, residents rarely regarded the renovation as an indication of a positive change for the neighborhood. This distinction relates to residents' ongoing preference for homeowner occupants. Residents believed for the most part that renters would occupy the renovated homes and residents did not consider renters to be sources of stability in the neighborhood.

(2) The second theme was residents' continued call for greater community cohesion. On several occasions, residents answered this call for cohesion by working together to remediate vacant lots. Many residents had pointed to vacant lots as a greater threat to stability than vacant homes. However, residents continued to express a desire for greater community cohesion and linking social capital needed to address the many threats besieging their neighborhood. They also continued to describe their neighborhoods' persistent social and institutional isolation from the rest of the city.

(3) Residents continued to reveal their preference for long-term homeowners, and they expressed their skepticism that the acquisition of the target homes by nonresident landlords would ultimately benefit the neighborhood.

Consistent with the qualitative findings, our quantitative data show little impact of home rehabilitation on either sense of community or on the conditions of nearby parcels. Neither our measure of neighbors' subjective sense of community nor our objective ratings of the parcel condition showed a significant positive effect due to proximity to a renovated 
property. Thus, it does not appear that the rehabilitated homes alone encourage neighbors to take better care of the physical condition of their homes or increases their sense of community.

\section{Conclusion}

This study investigated the social impact of abandoned home rehabilitation. Our qualitative data collected during on-site interviews with residents demonstrated that negative neighborhood social forces, such as fear of gun violence and child safety, cause residents much more concern than the negative impact of abandoned, foreclosed homes. Using a mixed methods approach, we found that the rehabilitation of abandoned homes has little social impact, and both the qualitative and quantitative data support this finding. The quantitative portion found a marginal effect of rehabilitation on community cohesion, though not in a positive direction. We employed two different regressions predicting "sense of community": the first used program status as predictor, and the second used rehabilitation status as predictor. Neither showed significant results for the impact of home rehabilitation on sense of community. A marginally significant association was observed with residents' sense of community, such that sense of community declined on blocks where renovations occurred. This is consistent with regressions that include parcel condition change. We surmise this may reflect the residents' belief that the newly rehabilitated homes would be occupied by strangers, i.e., renters, which they do not favor. In addition, walkability - but not safety - is associated with sense of community. This distinction may reflect subtleties about feelings of safety, as related to the dwelling unit and the block. Walkability concerns conditions on the block, which is more related to sense of community.

We presented our results around four major themes: (1) residents' indifference to foreclosures, (2) residents' keen awareness of other physical and social threats within their own neighborhood, (3) residents' confidence in the benefits of community cohesion, and (4) residents' belief in the community benefits of homeownership.

First, initial fieldwork suggested that most residents did not view abandoned, foreclosed homes as primary cause of negative social conditions in the neighborhood. Lack of interest in abandoned, foreclosed homes may not be surprising, given the relative stability in 
neighborhood social dynamics from year to year: the correlation for sense of community in both 2011 and 2012 among the interviewees was $r=0.67(p<.001)$. Further, there was limited difference in the physical conditions of the housing parcels on the blocks observed from Year 1 to Year 2.

Secondly, other neighborhood problems, especially crime and anti-social activity, were a source of great concern for residents in both Years 1 and 2 . Residents described the threatening presence of gang activity and prostitution but expressed their greatest level of concern about the prevalence of gun violence. Residents, in fact, ranked foreclosures as the least concerning community issue and safety at night as the top concern.

Thirdly, many participants suggested the need for greater community cohesion to facilitate social bonding within the neighborhood and linking to resources outside the neighborhood. Residents described greater community cohesion as a means to work together to achieve common goals and collectively advocate for their share of municipal resources, police services being chief among these. Findings also show the influence of homeownership. Residents identified homeowners as primary agents of stability. The data also confirm established findings about how homeownership being related to both physical and social conditions. Homeowners reported a higher sense of community than renters. Additionally, the level of housing distress was significantly lower on the homeownership parcels.

This study faced a number of problems that might have interfered with the production of statistically significant results. The first being the relatively small number of target properties and a small universe of participants. Sixteen target properties and, on average, 140 survey participants each year did not allow for much statistical power. In a somewhat related point, we chose to measure the sense of community for residents living in abutting parcels, as this measurement method mirrors those employed in the price and crime effects literature. However, it is possible that this logic does not apply for detecting changes in the social conditions of the neighborhood since these changes might be more diffuse.

Secondly, the program was not implemented as planned, and only half of the target properties were renovated during the study period, rather than all of them, as we had 
anticipated when designing our study. Thus, the quasi-experimental nature of the design was further compromised.

Context matters too. It may be unwise to generalize on the basis of findings obtained from disadvantaged neighborhoods in the northeastern United States, especially amidst the aftermath of the Great Recession. The national housing market - and the regional economy, more generally - differ markedly from conditions prevailing in cities such as those found in Southern United States or the Rust Belt.

Nonetheless, there are also several reasons to take these results -- that is that abandoned home rehabilitation has little impact on social conditions in the neighborhood, and when they do, the effects are negative -- seriously and to take that knowledge to inform policy making. . Despite the frequency of employing home rehabilitation in neighborhood revitalization strategies, there is little theoretical or empirical support to show how the effort leads to the desired outcomes, except in the case of price. And even here, price gains are modest, have not proven to be enduring nor linked to economic development within the neighborhood. In addition, findings in this study showing statistical significance are in line with previous findings: Homeownership is positively associated with sense of community and negatively associated with home distress, a consistency that lends a degree of validity to some of the other findings. Thirdly, our qualitative findings support our quantitative analyses. When we spoke to residents about home foreclosure and abandonment, they made it clear they do not see these developments as primary threats to neighborhood social conditions. So it is not surprising that they report little enthusiasm for home rehabilitation and re-occupancy as mechanisms for improving neighborhood social conditions. Rather, debilitating neighborhood dynamics, such as crime in general and gun violence in particular, concerned residents more acutely than foreclosures on their block. Anti-social activity engaged in by adults and youth contribute to a paralyzing lack of neighborhood safety, and an absence of opportunities to build social cohesion. Oversight of children and youth who live in these neighborhoods ranks high among adult concerns. Increasing the level of homeownership and community-level organizing are among the solutions residents propose. 
This study offers some policy suggestions based on the observations and experiences of neighborhood residents whom the policies are intended to reach. Most broadly, given the lack of results regarding the benefits housing rehabilitation, policymakers could start by questioning whether community development funding programs should support home rehabilitation as a means to improving social conditions. As noted above, the most frequent theme by residents was a call for community cohesion. Residents see community building as an essential means for improving social conditions by providing bonding and linking social capital. At a minimum, policies that provide funds for housing rehabilitation would do well to include explicit requirements that funding recipients also engage in community building. In our survey area, it is noteworthy to point out that only one instance of community building occurred, and it was initiated by neighbors, not by the NSP fund recipients. Given the expanding adoption of social media, community building can take many creative forms - from the traditional block party to Facebook groups. An added advantage of online social networking is that groups can easily link up to institutional actors, like the police (assuming the Police Department maintains a digital presence on social networking sites, such as Facebook, Twitter or Google Groups).

Residents' call for community, too, should be contextualized with residents' descriptions of a community in deep disarray. They view community building as instrumental to confronting the violence and disorder that define neighborhood life.

Second, residents are not only social capitalists, they are social structuralists. Residents know that one feature distinguishing disadvantaged neighborhoods from mainstream ones are levels of home ownership. A structural change - increasing the level of homeownership in the neighborhood - will benefit all residents. Policies aimed at helping residents become homeowners through proven mechanisms such as homeownership counseling and down payment assistance may also improve social conditions.

With a ready supply of consumers, the private sector might be incentivized to do the work of housing development. It would be unsound policy, however, to simply promote homeownership in the same disadvantaged neighborhoods that were the hardest hit by the foreclosure crisis of the Great Recession. Instead, we suggest that policy makers take a macro view beyond foreclosure intervention and traditional neighborhood revitalization to reduce 
neighborhood-level economic and social vulnerability. Many see the Community Reinvestment Act, which encourages banks to lend in low- and moderate-income neighborhoods, as a largescale and effective policy to bring marginalized neighborhoods into the mainstream economy. Others see it as only a first step. 


\section{Works Cited}

Apgar, W. C., Duda, M., Gorey, R. N., \& Council, H. P. (2005). The Municipal Cost of Foreclosures: A Chicago Case Study. Minneapolis, MN: Homeownership Preservation Foundation.

Bellair, P. E. (1997). Social interaction and community crime: Examining the importance of neighbor networks. Criminology, 35(4), 677-704.

Boston Police Department., (2009) 2009 Crime Summary.

Boston Redevelopment Authority( 2010) Census Tract and Block Group Geographies - 2000 \& $\underline{2010 .}$

Brodsky, A. E., O'Campo, P. J., \& Aronson, R. E. (1999). PSOC in community context: Multi-level correlates of a measure of psychological sense of community in low-income, urban neighborhoods. Journal of Community Psychology, 27(6), 659-679.

Brown, B. B., Perkins, D. D., \& Brown, G. (2004). Incivilities, place attachment and crime: Block and individual effects. Journal of environmental psychology, 24(3), 359-371.

Cantillon, D. (2006). Community social organization, parents, and peers as mediators of perceived neighborhood block characteristics on delinquent and prosocial activities. American Journal of Community Psychology, 37(1-2), 111-127

Clay, P. L. (1979). Neighborhood renewal: Middle-class resettlement and incumbent upgrading in American neighborhoods. Lexington, MA: Lexington Books.

Coleman, J. S. (1988). Social capital in the creation of human capital. American journal of sociology, S95-S120.

Cui, L. (2010). Foreclosure, vacancy and crime. (2010, November 1). Available at SSRN: http://ssrn.com/abstract=1773706 or http://dx.doi.org/10.2139/ssrn.1773706.

Davidson, W. B., \& Cotter, P. R. (1991). The relationship between sense of community and subjective well-being: A first look. Journal of Community Psychology, 19(3), 246-253.

Dillman, D. A. (2000). Mail and internet surveys: The tailored design method (Vol. 2). New York: Wiley.

Edmiston, K. D. (2012). Nonprofit housing investment and local area home values. Economic Review, (QI), 67-96. 
Elliott, D. S., Wilson, W. J., Huizinga, D., Sampson, R. J., Elliott, A., \& Rankin, B. (1996). The effects of neighborhood disadvantage on adolescent development. Journal of Research in Crime and Delinquency, 33(4), 389-426.

Gerardi, K., Rosenblatt, E., Willen, P. S., \& Yao, V. (2012). Foreclosure externalities: Some new evidence (NBER Working Paper No. 18353). Cambridge, MA: National Bureau of Economic Research. Available for purchase from www.nber.org/papers/w18353.

Goetz, E. G., Cooper, K., Thiele, B., \& Lam, H. K. (1997, February) The fiscal impacts of the St. Paul Houses to Homes Program (unpublished manuscript, Neighborhood Planning for Community Revitalization, Center for Urban and Regional Affairs). Minneapolis, MN: University of Minnesota.

Gonzales, N. A., Cauce, A. M., Friedman, R. J., \& Mason, C. A. (1996). Family, peer, and neighborhood influences on academic achievement among African-American adolescents: Oneyear prospective effects. American journal of community psychology, 24(3), 365-387.

Greenberg, S. W., Rohe, W. M., \& Williams, J. R. (1982). Safety in urban neighborhoods: A comparison of physical characteristics and informal territorial control in high and low crime neighborhoods. Population and Environment, 5(3), 141-165.

Hur, M., \& Morrow-Jones, H. (2008). Factors that influence residents' satisfaction with neighborhoods. Environment and Behavior, 40(5), 619-635.

Hurley, D. (2004 January 6), Scientist At Work--Felton Earls; On Crime As Science (A Neighbor At a Time), The New York Times, [section] F

Immergluck, D., \& Smith, G. (2006a). The external costs of foreclosure: The impact of singlefamily mortgage foreclosures on property values. Housing Policy Debate, 17(1), 57-79.

Immergluck, D., \& Smith, G. (2006b). The impact of single-family mortgage foreclosures on neighborhood crime. Housing Studies, 21(6), 851-866.

Jones, R. W., \& Pridemore, W. A. (2012). The foreclosure crisis and crime: Is housing-mortgage stress associated with violent and property Crime in US metropolitan areas? Social Science Quarterly, 93(3), 671-691.

Kirk, D. S., \& Hyra, D. S. (2012). Home Foreclosures and Community Crime: Causal or Spurious Association?*. Social Science Quarterly, 93(3), 648-670.

Lacoe, J. R., \& Ellen, I. G. (2012). Mortgage Foreclosures and the Shifting Context of Crime in Micro-Neighborhoods. [Is this a standalone report? If it is an article from a journal, you will need journal name, volume no. and page numbers.] 
Local Initiatives Support Coalition (2009) LISC Online Annual Report.

www.lisc.org/annualreport/2009

Lochner, K., Kawachi, I., \& Kennedy, B. P. (1999). Social capital: a guide to its measurement. Health \& place, 5(4), 259-270.

Narayan-Parker, D. (1999). Bonds and bridges: social capital and poverty (Vol. 2167). World Bank Publications.

Nasar, J. L., \& Julian, D. A. (1995). The psychological sense of community in the neighborhood. Journal of the American Planning Association, 61(2), 178-184.

National Vacant Properties Campaign. 2005. Vacant Properties: The True Cost to Communities

Nelson, Lisa, Mary Helen Petrus, and Francisca R-C. Richter (2011). "Neighborhood Recovery and NSP1: Implementation in Select Fourth District Communities." In CR Report. Cleveland, $\mathrm{OH}$ : Federal Reserve Bank of Cleveland.

Perkins, D. D., Wandersman, A., Rich, R. C., \& Taylor, R. B. (1993). The physical environment of street crime: Defensible space, territoriality and incivilities. Journal of Environmental Psychology, 13(1), 29-49.

Sampson, R. J., \& Wilson, W. J. (1995). 'Toward a theory of race, crime, and urban inequality. Race, crime, and justice: A reader, 177-190.

Schilling, L. M. (2002) The Revitalization of Vacant Properties. International City/County Management Association. Washington DC.

Schwartz, A. E., Ellen, I. G., Voicu, I., \& Schill, M. H. (2006). The external effects of place-based subsidized housing. Regional Science and Urban Economics, 36(6), 679-707.

Spelman, William. 1993. "Abandoned buildings: Magnets for Crime?" Journal of Criminal Justice, vol. 21(5), pp. 481-495.

Stone, W., \& Hughes, J. (2002). Social capital: Empirical meaning and measurement validity, Research paper number 27. Melbourne: Australian Institute of Family Studies.

Taylor, R. B., Shumaker, S. A., \& Gottfredson, S. D. (1985). Neighborhood-level links between physical features and local sentiments: Deterioration, fear of crime, and confidence. Journal of Architectural and Planning Research.

Umberger, M., Yerak, B \& T. Malone (2008, March 31). As owners default, lenders move in. Chicago Tribune. Retrieved from http://articles.chicagotribune.com/2008-03-

31/news/0803300393_1_property-values-lenders-foreclosed 
Wilson, J. Q., \& Kelling, G. L. (1982). Broken windows. Atlantic monthly, 249(3), 29-38.

Wood, M., Turnham, J., \& Mills, G. (2008). Housing affordability and family well-being: Results from the housing voucher evaluation. Housing Policy Debate, 19(2), 367-412

Woolcock, M. (1998). Social capital and economic development: Toward a theoretical synthesis and policy framework. Theory and society, 27(2), 151-208. 